\title{
Clinical Validity of the SWAL-QOL and SWAL-CARE Outcome Tools with Respect to Bolus Flow Measures
}

\author{
Colleen A. McHorney • Bonnie Martin-Harris • \\ JoAnne Robbins $\cdot$ John Rosenbek
}

Published online: 12 September 2008

(C) Springer Science+Business Media, LLC 2008

\section{Erratum to: DYSPHAGIA}

\section{DOI: $10.1007 / \mathrm{s} 00455-005-0026-9$}

In the publication of "Clinical Validity of the SWAL-QOL and SWAL-CARE Outcome Tools with Respect to Bolus Flow Measures" (Volume 21, Number 3, July 2006, pp. 141-148, DOI: 10.1007/s00455-005-0026-9) the first initial of the author Coyle in reference \# 26 was erroneously stated as M. It should be J Coyle.

The online version of the original article can be found under doi: 10.1007/s00455-005-0026-9

\section{A. McHorney}

Merck \& Co., Inc., West Point, PA, USA

B. Martin-Harris

Department of Otolaryngology-Head and Neck Surgery,

MUSC Evelyn Trammell Institute for Voice and Swallowing, and College of Health Professions, Medical University of South

Carolina, Charleston, South Carolina, USA

\section{J. Robbins}

William S. Middleton Memorial Veterans Hospital and University of Wisconsin-Madison Medical School,

Madison, Wisconsin, USA

J. Rosenbek

Department of Communicative Disorders, University of Florida, Gainesville, Florida, USA

J. Rosenbek

Department of Neurology, University of Florida

School of Medicine, Gainesville, Florida, USA

C. A. McHorney $(\bowtie)$

Merck Co., Inc., WP39-166, 770 Sumneytown Pike,

West Point, PA 19486, USA

e-mail: colleen_mchorney@merck.com
The correct list of authors for reference \# 26 is as follows:

Rosenbek J, Robbins J, Roecker E, Coyle J, Wood J 